\title{
Uma análise da evasão discente do curso de relações públicas da Unipampa - Campus São Borja
}

Valmor Rhoden

Pós-Doutor em Educação pela Universidade Federal de Santa Maria (UFSM). Doutor em Comunicação pela Pontifícia Universidade Católica do Rio Grande do Sul (PUCRS). Professor adjunto da Universidade Federal do Pampa (Unipampa) - Campus São Borja.

E-mail: vrhoden6@gmail.com

Fernanda Sagrilo Andres

Doutora em Comunicação pela Universidade Federal de Santa Maria (UFSM). Professora adjunta do curso de Relações Públicas da Universidade Federal do Pampa (Unipampa). E-mail: fersagrilo@gmail.com

Juliana Lima Moreira Rhoden

Doutora em Educação, psicóloga e professora adjunta da Universidade Federal do Pampa (Unipampa) - Campus São Borja.

E-mail: juli.rhoden@gmail.com

Resumo: A proposta deste artigo é analisar os dados relacionados ao fenômeno de evasão discente no curso de Relações Públicas da Universidade Federal do Pampa (Unipampa) - Campus São Borja e, então, fazer uma reflexão sobre essa questão. Para tanto, a metodologia empregada é a pesquisa bibliográfica, amparada pela análise documental. $O$ curso teve a sua primeira oferta em 2010-2, e o foco de análise deste trabalho está nas evasões compreendendo os anos de 2010 a 2017. O estudo aponta que o índice de evasão é alto, chegando a quase $60 \%$ no período analisado. Em vista disso, busca-se apresentar, nesta reflexão, estratégias que possam amenizar ou reverter essa realidade e ampliar o debate interno e entre a comunidade acadêmica da área de Relações Públicas a respeito da evasão no ensino superior.

Palavras-chave: relações públicas; evasão discente; Unipampa; ensino superior; São Borja.
Abstract: The purpose of this article is to analyze the data related to the phenomenon of student evasion in the Public Relations course at the Universidade Federal do Pampa (Unipampa) - São Borja Campus, and then reflect on this matter. The applied methodology is the bibliographical research, supported by document analysis. The first offer of the course was in 2010-2, and this article's focus of analysis lies on the dropouts comprising the years 2010 to 2017 . The study indicates that the evasion rate is high, reaching almost $60 \%$ in the analyzed period. In view of this, this reflection intends to present strategies that can soften or reverse such reality and broaden the debate within the educational institution and among the academic community of the Public Relations field regarding student evasion in higher education.

Keywords: Public Relations; student evasion; Unipampa; higher education; São Borja.
Recebido: 28/03/2018 
comunicação \& educação • Ano XXIII • número 2 • jul/dez 2018

\section{INTRODUÇÃO}

Apesar da significativa expansão do acesso ao ensino superior brasileiro nos últimos anos, a permanência dos alunos nesse nível é problemática. O fenômeno da evasão discente não é uma realidade que preocupa apenas as instituições privadas, pois até mesmo as universidades públicas estão se mobilizando e repensando ações para reduzir as desistências.

A partir da preocupação com essa problemática, este artigo tem o objetivo de refletir sobre as causas de evasão do curso de Relações Públicas da Universidade Federal do Pampa (Unipampa) - Campus São Borja, Rio Grande do Sul, e apontar possíveis estratégias que possam ser utilizadas pelo referido curso (colegiado, corpo docente, Núcleo de Desenvolvimento Estruturante e coordenação) para evitar continuidade das desistências.

O recorte utilizado considera o período de 2010-2 (início das atividades do curso) a 2017, quando foi suprimida a ênfase em Produção Cultural - foco da formação ao longo de sete anos -, por recomendação da Pró-Reitoria de Graduação (Prograd) ${ }^{1}$. Entende-se que este artigo, ao apresentar dados e uma leitura do contexto do curso de Relações Públicas da Unipampa - Campus São Borja, colabora com o debate sobre a evasão no ensino superior no Brasil, estabelecendo uma discussão que pode auxiliar os cursos a diminuírem os índices de desistência.

O Projeto Pedagógico de Curso (PPC) ajuda a introduzir o conhecimento sobre as origens da graduação em Relações Públicas oferecida pela instituição em estudo²:

1. Mensagem eletrônica recebida pela coordenação do curso, no dia 26 de abril de 2017, com o detaIhamento.

2. UNIVERSIDADE FEDERAL DO PAMPA. Projeto político-pedagógico do Curso de Relaçỗes Públicas da Unipampa. São Borja: Unipampa, 2015 Disponível em: <http:// cursos.unipampa.edu.br/ cursos/relacoespublicas/ pdi-ppc/>. Acesso em: 22 nov. 2017. p. 21

3. BRASIL. Ministério da Educação. Resolução nº 2, de 27 de setembro de 2013 . Institui as Diretrizes Curriculares Nacionais para os cursos de graduação em Relações Públicas. Diário Oficial da União, Poder Executivo, Brasília, DF, 1 out. 2013. Seção 1, p. 28-29. Disponível em: <http://goo.gl/ HIO2iM>. Acesso em: 2 out. 2014
O Curso de Relações Públicas foi criado com o objetivo de reforçar a área de Comunicação Social do campus de São Borja e atender às questões sociais e culturais da região. A sugestão de criação do curso se deu em reunião do Conselho de Campus no dia 03 de novembro de 2008 e a ata de homologação da comissão para criação do PPC foi em 16 de setembro de 2009. A criação do curso deu-se pela Portaria de autorização no Conselho Universitário - Portaria № 1776, de 07 de dezembro de 2011, tendo por base as decisões tomadas pelo Conselho Universitário no ano de 2009.

Desde o início do curso de Relações Públicas da Unipampa - Campus São Borja, em 2010, três estruturas curriculares foram implementadas, sendo a última de 2016, já com a incorporação das orientações das diretrizes curriculares nacionais específicas da área, publicadas em 2013³. O curso tem duração de quatro anos, distribuídos em oito semestres, com aulas no turno noturno, sendo a carga horária de 3.245 horas, contempladas em Componentes Curriculares Obrigatórios, incluindo Estágio Curricular Supervisionado Obrigatório em Relações Públicas (200 horas), Atividades Complementares de Graduação (200 horas) e Componentes Curriculares Complementares de Graduação (200 horas).

Para a construção deste texto, a metodologia empregada foi a pesquisa bibliográfica, amparada pela análise documental. Foram considerados como 
instrumentos de estudo os dados de evasão do Sistema de Informações para o Ensino (SIE) da Unipampa, obtidos por meio da Secretaria Acadêmica do campus São Borja. O referencial teórico que sustenta a questão de evasão discente está fundamentado nas reflexões de Ristoff ${ }^{4}$, Pacheco e Ristoff ${ }^{5}$, Madeira e Silva ${ }^{6}$ e Marini ${ }^{7}$.

\section{O ENSINO SUPERIOR DE RELAÇÕES PÚBLICAS NO BRASIL}

Ainda que a atividade de Relações Públicas no Brasil tenha se originado em 1914 e começado a se profissionalizar na década de 1950, foi só no fim dos anos 1960 que surgiu o primeiro curso superior da área no país. A graduação foi criada pela Universidade de São Paulo (USP), em 1967, quando foi sancionada a Lei $\mathrm{n}^{\mathrm{o}} 5.377^{8}$, que regulamenta a profissão. Segundo Ferrari, a questão de criar a lei e o curso superior, "por um lado, proporcionou a oportunidade de sistematizar o ensino e oferecer parâmetros ao mercado, por outro 'engessou' a atividade criando um rígido sistema de controle de seu exercício por meio da fiscalização dos Conselhos Regionais"'.

Os documentos do Ministério da Educação (MEC) que determinam os currículos da formação em Relações Públicas datam dos anos de 1969, 1978 e 1984, e há também as Diretrizes Curriculares Nacionais de Relações Públicas, de 2002 e de 2013, estas últimas específicas, sendo que os cursos tiveram até o final de 2015 para implementá-las ${ }^{10}$. Entre as principais mudanças trazidas pela documentação estão: o aumento de carga horária, os eixos de formação e a regulamentação do estágio, que passou a ser obrigatório.

São cerca de 70 cursos superiores na área em funcionamento no país, segundo o Instituto Nacional de Estudos e Pesquisas Educacionais Anísio Teixeira $(\text { Inep/MEC) })^{11}$. No estado do Rio Grande do Sul, onde está a Unipampa, são 13 cursos em funcionamento. Destes, quatro são oferecidos por instituições de ensino superior (IES) públicas e nove por IES privadas, sendo um a distância. Os cursos de instituições públicas, todos presenciais, são ofertados na: Universidade Federal de Santa Maria (UFSM, campi de Santa Maria e Frederico Westphalen), Unipampa (São Borja) e Universidade Federal do Rio Grande do Sul (UFGRS, Porto Alegre). Já os cursos privados são ofertados pelas instituições: Centro Universitário da Serra Gaúcha (FSG, Caxias do Sul), UniRitter (Porto Alegre), Faccat (Taquara), Universidade de Caxias do Sul (UCS, Caxias do Sul), Universidade Feevale (Novo Hamburgo), Universidade de Santa Cruz do Sul (UNISC, Santa Cruz do Sul), Unisinos (São Leopoldo - presencial), Pontifícia Universidade Católica do Rio Grande do Sul (PUCRS, Porto Alegre) e Unisinos (São Leopoldo - EAD), sendo este último o único a distância.

O curso de Relações Públicas da Unipampa foi criado com o objetivo de refor-

çar a área de Comunicação Social do campus de São Borja, considerando-se que já existiam as graduações em Jornalismo e Publicidade e Propaganda. Além disso,

4. RISTOFF, Dilvo I. Construindo outra educação: tendências e desafios da educação brasileira. Florianópolis: Insular, 2011.

5. PACHECO, Eliezer; RISTOFF, Dilvo I. Educação superior: democratizando o acesso. Brasília, DF: Instituto Nacional de Estudos e Pesquisas Educacionais, 2004. (Série Documental, Textos para Discussão n. 12).

6. MADEIRA, Miguel Carlos; SILVA, Rosa Maria Alves. Ensinar na universidade: didática para professores iniciantes. Petrópolis: Vozes, 2015

7. MARINI, Thereza. A função do ensino e a formação do professor universitário. São Paulo: Paulus, 2013

8. BRASIL. Lei n ${ }^{\circ} 5.377$, de 11 de dezembro de 1967. Disciplina a Profissão de Relações Públicas e dá outras providências. Diário Oficial da União, Poder Legislativo, Brasília, DF, 12 dez. 1967. Seção 1, p. 12447. Disponível em: <http://www.planalto.gov.br/ccivil_03/leis/ 1950-1969/L5377.htm>. Acesso em: 6 dez. 2018.

9. FERRARI, Maria Aparecida. A prática das relações públicas no cenário brasileiro e latino-americano. In: GRUNIG, James E.; FERRARI, Maria Aparecida; FRANÇA, Fábio. Relações públicas: teoria, contexto e relacionamentos. 2. ed. São Caetano do Sul: Difusão, 2011. p. 205.

10.MOURA, Cláudia Peixoto. $O$ curso de comunicação social no Brasil: do currículo mínimo às novas diretrizes curriculares. Porto Alegre: EdiPUCRS, 2002.

11. RHODEN, Valmor. O ensino superior de relações públicas: formação digital, práticas e desafios na UFSM. 2013. $331 \mathrm{f}$. Tese (Doutorado em Comunicação Social) - Pontifícia Universidade Católica do Rio Grande do Sul, Porto Alegre, 2013. 
12. UNIVERSIDADE FEDERAL DO PAMPA, 2015.

13. RISTOFF, Dilvo I. Universidade em foco: reflexões sobre a educação superior. Florianópolis: Insular, 1999.

14. MADEIRA; SILVA, op cit., p. 237.

15. BRASIL. Ministério da Educação. Comissão Especial de Estudos sobre Evasão nas Universidades Públicas Brasileiras. Diplomação, retenção e evasão nos cursos de graduação em instituições de ensino superior públicas. Brasília, DF: Andifes, 1996. Disponível em: < http://www. dominiopublico.gov.br/ pesquisa/PesquisaObra Form.jsp>. Acesso em: 30 nov. 2017

16.PACHECO; RISTOFF, op. cit., p. 9. tinha-se como foco atender às questões sociais e culturais da região fronteiriça entre o estado do Rio Grande do Sul e a Argentina. De acordo com o PPC do curso ${ }^{12}$, a graduação propicia ao estudante conhecimento teórico e metodológico, com base nas especificidades conceituais e práticas das Relações Públicas. Em linhas gerais, o acadêmico do curso da Unipampa, a partir do desenvolvimento de habilidades e competências e de capacitação crítica, atua na gestão da comunicação e do relacionamento entre as organizações e seus públicos de interesse.

\section{A EVASÃO NO ENSINO SUPERIOR NO BRASIL}

Mesmo diante do cenário de ampliação do acesso ao ensino superior no país, com políticas públicas que caminham para essa situação, reorganização do financiamento estudantil, criação de vagas públicas, inserção do Exame Nacional do Ensino Médio (Enem) nos processos seletivos e inclusão de cotas sociais e étnicas, a permanência dos alunos nas universidades é preocupante, e um dos indícios de tal situação é o fenômeno da evasão discente.

A questão é complexa, mediada e movida por diferentes fatores, podendo também ser analisada por ângulos distintos: por curso ou instituição, ou em relação ao sistema de ensino superior. De acordo com Ristoff ${ }^{13}$, existe a chamada evasão de mobilidade, que ocorre pelo processo migratório do estudante para outro curso, seja dentro da mesma universidade, seja em outra instituição. O aluno apenas troca de curso, permanecendo no sistema.

Outro tipo de evasão é apontado por Madeira e Silva" ${ }^{14}$, chamado de "pós-escolar”, o qual indica que o indivíduo, mesmo após experimentar a sensação de incompatibilidade entre sua vocação e o andamento do curso, prefere concluir o estudo. No entanto, já no mundo do trabalho, passa a demonstrar insatisfação com a profissão, abdicando desta. Os autores mostram um dado que evidencia que cerca de $50 \%$ dos diplomados atuam em áreas que pouco ou nada têm de relação com o curso superior que frequentaram. Para o MEC, o conceito de evasão dos cursos de graduação é entendido como a ação de saída de um aluno de seu curso de modo definitivo, sem que este tenha sido concluído ${ }^{15}$.

Neste trabalho, a evasão é entendida como a saída do aluno do seu curso de origem, definitiva ou temporariamente, por qualquer motivo, exceto a diplomação. Nessa perspectiva, um dos motivos de abandono observados, talvez o mais notório, refere-se à condição socioeconômica. Segundo dados de Pacheco e Ristoff ${ }^{16}$, "25\% dos potenciais alunos universitários são tão carentes que não têm condições de se manterem na educação superior, mesmo se esta for gratuita”. Ou seja, a questão econômica é um forte apelo à desistência, porém, ele não é o único: há várias outras situações de ordem pessoal ou institucional que podem atuar como fatores mobilizadores para a evasão.

Há ainda a questão que se deve às oportunidades ofertadas, pois nem sempre a escolha do curso corresponde ao interesse pessoal do aluno, mas sim à sua necessidade. 
Fatores socioeconômicos pressionam o jovem a "escolher" esse ou aquele curso, por determinação do mercado de trabalho, o que nem sempre corresponde à sua "vocação". Curso que não se ajusta com sua aptidão natural gera uma falta de sintonia entre o que o aluno espera de um curso e o que este lhe oferece ${ }^{17}$.

A imaturidade dos estudantes, a falta de informação sobre o curso, a opção disponibilizada e as influências familiares podem provocar uma entrada precoce ou indesejada no curso de Relações Públicas. Essas questões tendem a refletir na não continuidade dos estudos acadêmicos, pois, ao perceberem que agiram movidos por outras expectativas a respeito da instituição ou da profissão escolhida, os graduandos passam a considerar a possibilidade de desistência. Outro aspecto a ser destacado é a repetência em componentes curriculares, sendo este um dos fatores desmotivadores que podem induzir ao abandono do curso. Nesse quesito, observa-se que há carência de formação adequada, um problema herdado ainda da educação básica.

Assim, observa-se que a evasão nas universidades públicas é preocupante, uma vez que vem crescendo, gradativamente, por motivos predominantes em nível nacional, como a falta de informação sobre os cursos e a dificuldade dos alunos de acompanharem as aulas, em razão de terem cursado um ensino médio com muitas fragilidades em termos de qualidade ${ }^{18}$. Uma pesquisa realizada em 2008, no estado de São Paulo, mostrou que a média de evasões no "ensino privado era de 21,10\%, enquanto no ensino público foi de 14,4\%"19.

Os principais motivos de evasão no ensino superior brasileiro estão relacionados a uma conjugação de diversos fatores ligados a problemas financeiros, de adaptação, incompatibilidade de horário de trabalho com estudos, entre outros. Porém, ainda de forma geral, as instituições de ensino se preocupam mais com o ingresso do aluno e menos em como mantê-lo. Portanto observa-se que, no atual panorama educacional, ocorreram mudanças em formas excludentes, pois, se antes ela se dava prioritariamente pela contenção na forma de acesso, hoje a exclusão se faz no interior do sistema de ensino superior.

\section{A EVASÃO NO CURSO DE RELAÇÕES PÚBLICAS DA UNIPAMPA}

Fazendo um recorte da realidade local e tendo em vista o âmbito cultural fronteiriço, este trabalho tem a intenção de mapear a situação total de evasões desde o início das atividades do curso de Relações Públicas da Unipampa. É oportuno salientar as diferenças culturais encontradas na cidade sede do curso, o município de São Borja, no Rio Grande do Sul. O local que acolhe os estudantes é banhado pelo Rio Uruguai e fica ao lado de Santo Tomé, Corrientes, na Argentina. Sua economia está vinculada basicamente ao setor primário da cadeia produtiva, mais precisamente de grãos de arroz, trigo e soja, e à criação de bovinos de corte. A cidade de pequeno porte, com 62.808 habitantes, segundo a estimativa de 2017 do Instituto Brasileiro de Geografia e Estatística (IBGE) ${ }^{20}$,

17. MARINI, op. cit., p. 37. 18. MADEIRA; SILVA, op. cit. 19. Ibidem, p. 233. 20. INSTITUTO BRASILEIRO DEGEOGRAFIAEESTATÍSTICA. São Borja. IBGE Cidades, Rio de Janeiro, 2017 Disponível em: <https:// cidades.ibge.gov.br/brasil/ rs/sao-borja/panorama>. Acesso em: 5 mar. 2018. 
propicia poucas opções de estágio e de atividades profissionais, tanto para aqueles que chegam buscando ingressar na universidade quanto para aqueles que pretendem continuar morando em São Borja após a formação acadêmica. Tendo isso em vista, salienta-se que a implantação da Unipampa foi marcada justamente para contribuir para a integração e o desenvolvimento das regiões de fronteira do Brasil com os países vizinhos, Uruguai e Argentina, buscando a expansão e a renovação das instituições federais de educação superior.

A partir desse panorama contextual, definiu-se como eixo de análise deste estudo a evasão no ensino superior, considerando-se sua relevância sociológica relacionada à permanência de estudantes no nível de graduação e na universidade pública, de modo a averiguar os dados do curso de Relações Públicas da Unipampa. Os dados sistematizados no Quadro 1, fornecidos pela Secretaria Acadêmica do campus São Borja, compreendem o período de 2010 a 2017.

\section{Quadro 1: Total de evasões no curso por semestre letivo}

\begin{tabular}{|c|c|c|}
\hline Ano/Semestre & $1^{\circ}$ & $2^{\circ}$ \\
\hline 2010 & 2 & 12 \\
\hline 2011 & 9 & 18 \\
\hline 2012 & 11 & 25 \\
\hline 2013 & 21 & 18 \\
\hline 2014 & 18 & 24 \\
\hline 2015 & 13 & 22 \\
\hline 2016 & 22 & 27 \\
\hline 2017 & 11 & 0 \\
\hline
\end{tabular}

Fonte: Elaboração dos autores.

21.As aulas começaram no segundo semestre letivo, porém o ingresso pelo Sisu ocorreu no primeiro semestre.
Levou-se em consideração o conceito de evasão compreendido como a saída do estudante de Relações Públicas do respectivo curso, definitiva ou temporariamente, sem a diplomação. Sendo assim, o número total de evasões até o presente momento é de 253 alunos, o que corresponde a uma taxa de $58,75 \%$ dos ingressantes desde o início do curso, em 2010, com um total de oito processos de ingresso, com 50 vagas cada. Isso significa que mais da metade dos alunos desistiram ou postergaram a conclusão do curso de ensino superior em Relações Públicas na instituição estudada.

O primeiro processo seletivo do curso foi realizado pelo Sistema de Seleção Unificada do Ministério da Educação (Sisu), em 2009, para ingresso no segundo semestre de $2010^{21}$. Analisando-se apenas o semestre letivo, e não o ano todo, o processo em que houve maior evasão foi o de 2017-2, e o de menor evasão, não sendo contabilizada nenhuma desistência, foi o primeiro semestre letivo do curso, 2010-2. Isso pode ser observado no Gráfico 1. 
Gráfico 1: Total de evasões no curso por ano, de 2010 a 2017

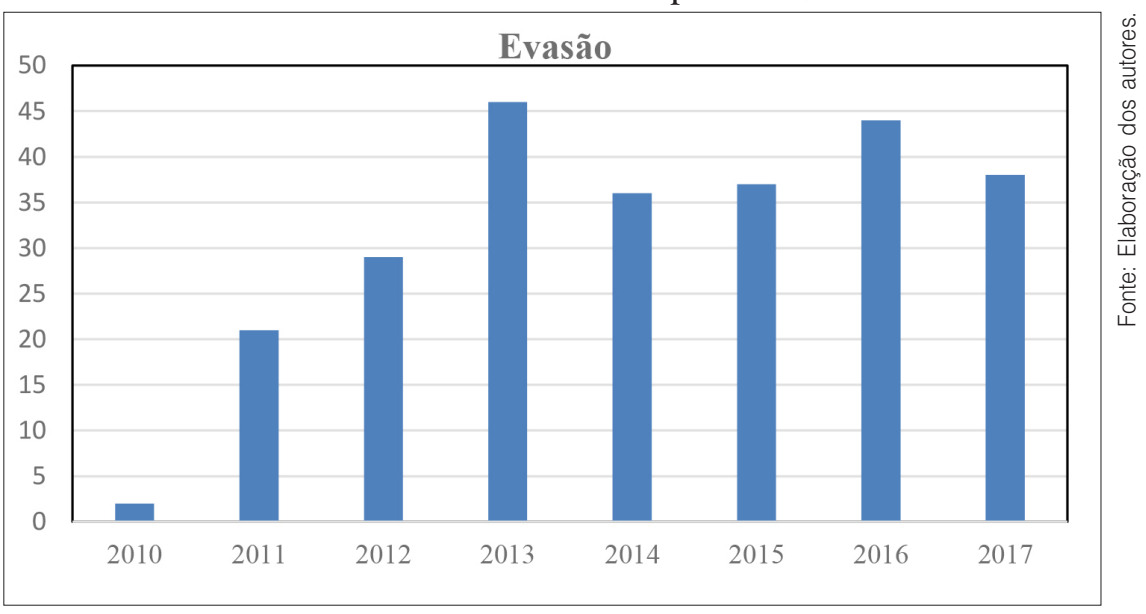

$\mathrm{Na}$ relação evasões/ano, a maior taxa foi constatada em 2013, quando houve o registro de saída de 46 alunos. De 2014 a 2016 o número de evasões foi crescente, diminuindo um pouco em 2017, e os menores índices foram registrados entre 2010 e 2012.

No momento em que o aluno efetiva uma alteração de seu vínculo com a instituição, ele precisa justificar o motivo para isso, de modo que seja elaborado um banco de dados para a respectiva IES. Considerando tal aspecto, em relação à origem das evasões do curso de Relações Públicas da Unipampa, os dados do Gráfico 2 demonstram, entre as desistências do período estudado, as seguintes motivações: abandono (79\%), cancelamento (9\%), transferência interna $(8 \%)$, desligamento $(3 \%)$ e transferência externa $(1 \%)$.

Gráfico 2: Motivo da evasão

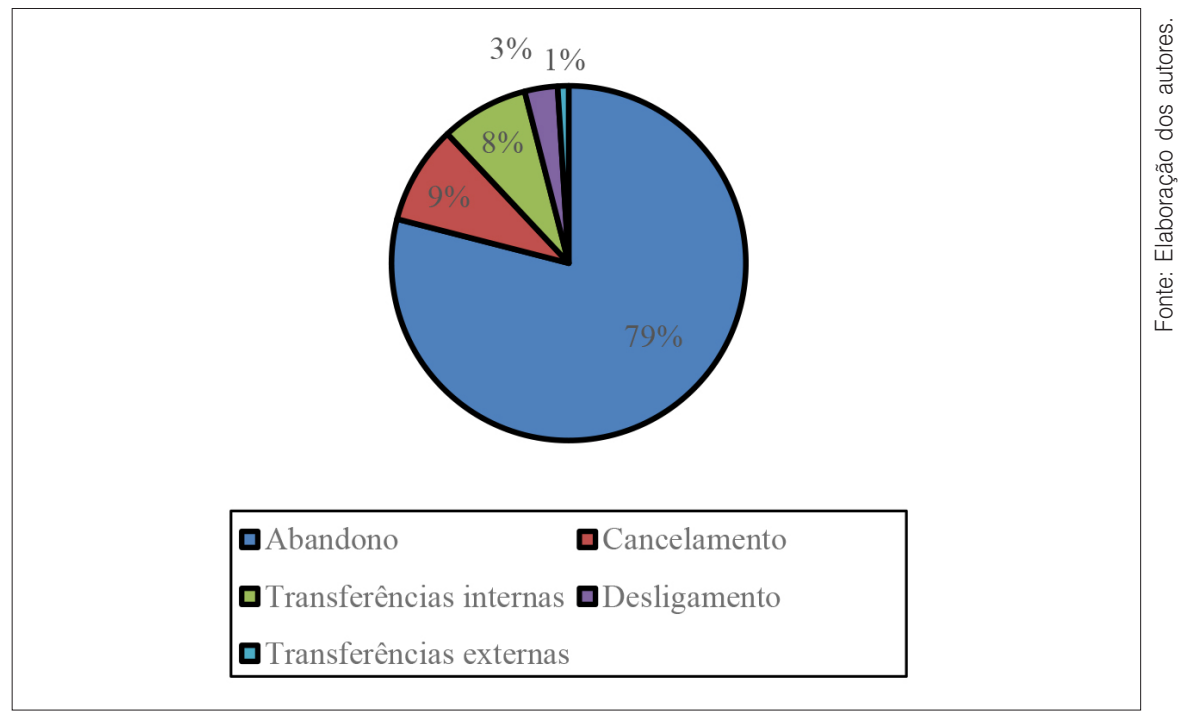

A Resolução no 29 da Unipampa ${ }^{22}$, de 28 de abril 2011, cita seis tipologias de evasão ${ }^{23}$ : (1) abandono de curso, que ocorre quando não há confirmação de matrícula

22. UNIVERSIDADE FEDERAL DO PAMPA. Conselho Universitário. Resolução $n^{\circ}$ 29, de 28 de abril de 2011. Aprova as normas básicas de graduação, controle e registro das atividades acadêmicas. Bagé: Conselho Universitário, 2011. Disponível em: < http://portei ras.r.unipampa.edu.br/por tais/prograd/files/2011/06/ Resolu\%C3\%A7\%C3\%A30 -29-2011-Normas-B\% C3\%A1sicas-de-Gradua\% C3\%A7\%C3\%A3o.pdf>. Acesso em: 4 dez. 2017.

23. Para esta pesquisa, não foi utilizada a categoria "óbito", sendo analisadas apenas as tipologias relacionadas diretamente ao processo de ingresso. 
ou trancamento para o semestre vigente; (2) cancelamento, que ocorre quando o próprio aluno ou seu representante legal solicita o cancelamento de matrícula, com a finalidade de perder o vínculo, em virtude de ter conseguido matrícula em outro curso, outra IES e/ou por algum outro motivo pessoal; (3) desligamento, que ocorre quando o acadêmico tem reprovações por frequência em todas as disciplinas matriculadas no semestre, por dois semestres consecutivos e/ou três semestres intercalados, e também ocorre quando o estudante ultrapassa o tempo máximo de integralização curricular; (4) reopção, que ocorre quando o aluno solicita transferência interna para algum outro curso da IES, neste caso a Unipampa - para isso, os alunos utilizam o Edital de Reopção de Curso (configurando uma evasão do curso, e não da instituição ou do ensino superior); (5) transferência, que ocorre quando o estudante consegue transferência externa, para outra IES (configurando uma evasão do curso e da instituição, mas não do ensino superior); (6) óbito, que ocorre quando o indivíduo não confirma a vaga em razão de seu falecimento.

Ao analisar apenas o último período, ou seja, o ano de 2017, com os dados da Secretaria Acadêmica do Campus, percebe-se que a maioria das motivações da evasão foram abandonos, totalizando $79 \%$, ou seja, estes não configuram ainda o desligamento definitivo. A quantidade de desligamentos foi de 2,6\%, mesmo percentual de transferência externa. Outros 7,9\% foram de cancelamentos, mesmo percentual de reopção para outro curso da instituição. Para tal situação, há uma hipótese que merece ser aprofundada, ao se supor que algumas evasões tenham ocorrido em função de uma parcela significativa dos acadêmicos do curso trabalharem (o curso é noturno). Estes podem ter sido penalizados em função da crise econômica que o país está passando, que também influenciou nas suas vidas, e por isso não conseguem conciliar estudo e trabalho - mas isso vai ser um dos focos da segunda etapa da pesquisa, que será aplicada com os egressos.

A importância desse tipo de análise interna das instituições de ensino, a respeito da evasão, é evidenciada por Filho et al. ${ }^{24}$ :

O estudo interno, realizado por uma IES com base em seus dados, pode ser muitas vezes mais detalhado porque é possível institucionalizar-se um mecanismo de acompanhamento da evasão, registrando os diversos casos, agrupando e analisando subgrupos, ou diferentes situações [...] e, a partir daí, [...] buscar formas de combatê-las com fundamento nos resultados.

Nesse sentido, o propósito de escrever sobre a evasão no curso de Relações Públicas da Unipampa é encontrar uma forma de entender esse complexo problema, considerando-se um determinado caso em que ele se destaca. Desse modo, entende-se que esta discussão possa servir de subsídio para que, no

24. SILVA FILHO, Roberto Leal Lobo et al. Evasão no ensino superior brasileiro. Cadernos de Pesquisa, São Paulo, v. 37, n. 132, p. 641-659, set./dez. 2007. p. 644 . âmbito do curso e até mesmo do campus São Borja de modo geral, possam ser pensadas ações para diminuir os índices de evasão num momento em que o acesso ao ensino superior demonstra crescimento, se analisados os números da última década no Brasil. Como frisado anteriormente, o ingresso aumentou, mas é preciso investir mais fortemente para manter os alunos nas IES. 
A Unipampa realizou um estudo preliminar sobre a evasão dos cursos, com o objetivo de conhecer essa realidade institucional, no ano de 2011. Como destacado no documento, o propósito é "diagnosticar quali e quantitativamente os fatores que estão levando estudantes a evadirem, numa quantidade significativa” ${ }^{25}$. Nessa oportunidade, a pesquisa apontou que a gratuidade do ensino pode fazer com que alguns alunos optem pelos cursos em razão de não terem alternativa e precisarem de uma formação universitária para entrarem mais facilmente no mercado de trabalho. Isso significa que problemas no momento da escolha podem realmente ser fatores que causam evasão.

O curso de Relações Públicas também realizou um primeiro estudo sobre a evasão de alunos em 2013. Um questionário foi aplicado para os estudantes, e os principais resultados dessa investigação ${ }^{26}$ indicaram:

que $77 \%$ dos evadidos tinham como primeira opção para graduação o curso de Relações Públicas, assim como a maior parte (83\%) era da cidade de São Borja. Dos alunos que responderam o questionário, $55 \%$ exercem ou exerciam, na época do curso, atividade remunerada. No geral os professores foram bem avaliados, tendo sido apontados como pontos positivos: habilidade em despertar o interesse dos alunos, realização de avaliações compatíveis com o conteúdo de aula, cumprimento dos horários e flexibilidade no atendimento fora do horário de aula. Nas disciplinas apontadas no quesito dificuldade no aprendizado se encontram aquelas já esperadas, por abordarem temas complexos e terem grande carga teórica, com ressalva da disciplina de criação e produção gráfica, que foi apontada devido a problemas de frequência do professor e incompatibilidade de conteúdo. O campus teve sua infraestrutura avaliada como satisfatória, com exceção das salas de aula, onde foi apontada a necessidade de mais equipamentos. Em relação ao curso é possível notar que os alunos evadidos estavam de acordo com a grade curricular ofertada e em sua maioria conheciam os representantes discentes e docentes, tinham fácil acesso a esses representantes e eram constantemente informados das decisões tomadas pelo conselho de curso. O fato de ter sido apontada a pouca prática profissional foi creditado à desistência precoce dos alunos entrevistados, pois as disciplinas práticas se concentram após o $3^{0}$ semestre do curso.

Naquela época, as informações obtidas pela pesquisa foram compartilhadas em reunião do colegiado e, posteriormente, também levadas para a direção do campus. O curso fez, então, alterações curriculares, e questões que cabiam ao colegiado foram encaminhadas; porém, quanto aos índices de evasão, estes aumentaram cada vez mais, não tendo as alterações surtido efeito prático - ou seja, tais medidas carecem de novos olhares e medidas.

Importante salientar também que os dados desta pesquisa, aqui descritos, foram apresentados ao Núcleo de Desenvolvimento Estruturante (NDE) do curso e à Comissão de Curso no início do segundo semestre letivo de 2018, pois pensamos que a pesquisa realizada precisaria de ações em conjunto. Além disso, os dados também foram repassados para o Núcleo de Desenvolvimento Educacional (NuDe) e para a Direção do Campus.

Com base neste relatório, é possível afirmar que o problema da evasão deve ser analisado em três situações diferentes e interdependentes: contexto
25. UNIVERSIDADE FEDERAL DO PAMPA. Coordenadoria de Apoio Pedagógico. A evasão na Unipampa: diagnosticando processos, acompanhando trajetórias e itinerários de formação. Responsáveis: Adriano Rodrigues José e Giovani Souza Andreoli. Bagé: CAP, 2011. Disponível em: < http://porteiras.r.uni pampa.edu.br/portais/ cap/files/2010/07/Relat\% C3\%B3rio final evas\% C3\%A3o-na-UNIPAMPA out20111.pdf>. Acesso em: 30 nov. 2017. p. 114.

26. UNIVERSIDADE FEDERAL DO PAMPA. Curso de Relações Públicas. Pesquisa de evasão do Curso de Relações Públicas -Ênfase em Produção Cultural. Relatório impresso, disponível na Coordenação do Curso. São Borja: Unipampa, 2013. p. 9. 
27. BARDAGI, Marucia Patta; HUTZ, Cláudio Simon. "Não havia outra saída": percepções de alunos evadidos sobre o abandono do curso superior. Psico-USF Campinas, v. 14, n. 1, p. 95 105, jan./abr. 2009. Disponível em: <http://www. scielo.br/pdf/pusf/v14n1/ a10v14n1.pdf>. Acesso em: 8 out. 2018.

28. QUADROS, Daiane Franciele Morais. A evasão discente na universidade: o caso da UEPG. In: CONGRESSO NACIONAL DE EDUCAÇÃO, 11., 2013, Curitiba. Anais... Curitiba: Champagnat, 2013. p. 3065-3074. Disponível em: <http://educere bruc.com.br/arquivo/ pdf2013/8167_4450.pdf>. Acesso em: 8 out. 2018.

29. Isto vemos como um aspecto positivo, pois há mercado a ser desbravado na cidade e na região. Inclusive, começam, mesmo que timidamente, a surgir agências. Esse cenário é melhor do que o de uma saturação de mercado, no qual não há perspectivas de atuação ou avanços.

30. FERRARI, Maria Aparecida; GROHS, Ana Cristina da Costa Piletti. Perfil e trajetória dos egressos de relações públicas da ECA/ USP: subsídios para excelência acadêmica e competitividade no mercado de trabalho. In: CONGRESSO BRASILEIRO CIENTÍFICO DE COMUNICAÇÃO ORGANIZACIONALE RELAÇÕES PÚBLICAS, 9., 2015, Porto Alegre. Anais... Porto Alegre: EdiPUCRS, 2015. p. 130.

31. MADEIRA; SILVA, op. cit., p. 238-243. interno da instituição, contexto externo a ela e características individuais dos estudantes. Os estudantes estão inseridos em tais conjunturas; logo, estas não podem ser tratadas de maneira desvinculada, pois a falta de apoio em qualquer uma das categorias elencadas interferirá nas demais.

A maioria dos trabalhos científicos sobre a evasão no ensino superior no Brasil concentram esforços para entender seus conceitos e principalmente pesquisar suas motivações, como fizeram Bardagi e Hutz ${ }^{27}$ e Quadros ${ }^{28}$, sendo o primeiro oriundo de uma tese de doutorado. Poucos tratam de estratégias para diminuir tal situação e, nesse sentido, este trabalho se diferencia.

\section{CONSIDERAÇÕES FINAIS E PROPOSTA DE FUTURAS PESQUISAS}

Os dados apontados na pesquisa sobre a evasão discente no curso de Relações Públicas da Unipampa mostram um índice muito alto e preocupante. Nos primeiros sete anos de curso, mais da metade dos alunos evadiram. Esse fator, por si só, merece atenção e estudo e, consequentemente, ações das partes envolvidas (curso e IES).

Importante salientar que não encontramos estudos científicos divulgados sobre a realidade dos cursos de Relações Públicas no Brasil relativos à evasão discente. Essa realidade traz dificuldades de comparativos com outras realidades da mesma área, mas, por outro lado, evidencia o ineditismo e a originalidade deste trabalho.

Faz sentido, neste momento, refletir sobre as particularidades que contextualizam e, ao mesmo tempo, são específicas do curso de Relações Públicas da Unipampa: (1) o curso é recente, com apenas oito turmas formadas; (2) o curso é gratuito e, logo, acaba sendo a única opção para muitos cidadãos que pretendem ingressar em uma universidade pública, ainda que a graduação em Relações Públicas não seja a sua primeira escolha; (3) o curso é noturno e, portanto, torna-se opção para as pessoas que desejam estudar, mas trabalham durante o dia; (4) o curso está localizado em uma região fronteiriça, onde o mercado de Comunicação e de Relações Públicas, de modo específico, ainda não está desenvolvido ${ }^{29}$; (5) as informações sobre o que é e o que faz o profissional de Relações Públicas não são propriamente difundidas na sociedade e, ao ingressarem no curso, os estudantes muitas vezes acabam se deparando com um cenário completamente diferente daquele imaginado por eles.

Ademais, ainda existe uma questão mais ampla e que envolve todos os cursos de Relações Públicas atualmente: a discussão sobre os conteúdos essenciais, no ensino superior, para o bom desempenho da atividade profissional. "Embora seja uma atividade de gestão da comunicação, as Relações Públicas no Brasil enfrentam dificuldades para serem reconhecidas e legitimadas, seja no mercado de trabalho, como junto a sociedade em geral" ${ }^{30}$. Essas são algumas das situações que mostram o panorama atual das dificuldades do ensino superior e levam a um número expressivo de evasões.

Com base no exposto, o desafio está em pensar nas possibilidades para diminuir a evasão. Madeira e Silva trazem algumas sugestões ${ }^{31}$, sendo o eixo central "a 
aproximação do professor com o aluno”. Eles apresentam a proposta de criação de um espaço oficial para entrevistas individuais, no qual os alunos possam pedir conselhos, tirar dúvidas, e assim por diante, através de horários de atendimento realmente efetivos.

Outra sugestão é reorganizar a estrutura curricular, integrando os primeiros semestres do curso com temas inerentes à profissão e aplicando uma metodologia que propicie a articulação com a prática. Nesse sentido, a aproximação com empresas e o mundo do trabalho pode vir a gerar motivação nos alunos e mostrar expectativas e a realidade da prática profissional, um elemento fundamental para que o estudante saiba se posicionar na profissão após o término do curso.

Com relação à vivência acadêmica, a evasão também pode ser atenuada por meio de programas de nivelamento, uma estratégia que tende a amenizar deficiências de escolarização advindas dos níveis fundamental e médio, de modo a acelerar a adaptação dos graduandos na estrutura universitária.

Outra solução seria a elaboração de um projeto de apoio pedagógico, com a participação dos docentes do curso - um documento com o objetivo de desenvolver plantões de atendimento, criando-se assim espaço para ouvir os alunos, orientá-los e sanar ou minimizar suas dúvidas.

Nesse sentido, também se pode pensar em estruturar ambientes de monitoria, por meio dos quais os alunos mais experientes auxiliem os novatos, mediante recebimento de incentivo financeiro ou não. Ainda, é possível programar cursos de extensão para demandas específicas, elaborados a partir de diagnóstico obtido por meio de pesquisa feita com os alunos, para que as principais necessidades e/ou deficiências da formação sejam sanadas. Ademais, é também fundamental oferecer algum tipo de acompanhamento aos discentes.

Como destacado neste estudo, é perceptível o maior acesso ao ensino superior no Brasil, mas não há garantia de permanência. As medidas apontadas aqui, em vista da breve reflexão apresentada, podem não sanar o problema, mas prevenir o agravamento do quadro. $\mathrm{O}$ apontamento de tais estratégias corrobora o propósito inicial deste estudo, que é o de evidenciar o tema da evasão no ensino superior, considerando-se que, para tanto, é vital o debate entre IES e comunidade acadêmica, de modo a apontar algumas alternativas e ampliar o conhecimento da questão.

Nesse ínterim, observa-se que o desenvolvimento de mais pesquisas é importante para dar continuidade aos estudos da temática, de modo que os cursos e as instituições universitárias consigam ter base reflexiva para criar práticas de retenção de alunos, contribuindo para o desenvolvimento e a manutenção do ensino superior público.

A próxima etapa do nosso trabalho será realizar uma pesquisa com os alunos desistentes, buscando entender as diversas motivações que possam tê-los levado a abandonar a graduação em Relações Públicas. Depois, refletir sobre as frustrações e/ou expectativas desses sujeitos e, a partir das informações coletadas, ampliar a observação e continuar buscando soluções de prevenção para a evasão discente, almejando a futura diminuição dos indicadores. 
comunicação \& educação • Ano XXIII • número 2 • jul/dez 2018

\section{REFERÊNCIAS BIBLIOGRÁFICAS}

BARDAGI, Marucia Patta; HUTZ, Cláudio Simon. "Não havia outra saída": percepções de alunos evadidos sobre o abandono do curso superior. PsicoUSF, Campinas, v. 14, n. 1, p. 95-105, jan./abr. 2009. Disponível em: <http:// www.scielo.br/pdf/pusf/v14n1/a10v14n1.pdf $>$. Acesso em: 8 out. 2018.

BRASIL. Lei no 5.377, de 11 de dezembro de 1967. Disciplina a Profissão de Relações Públicas e dá outras providências. Diário Oficial da União, Poder Legislativo, Brasília, DF, 12 dez. 1967. Seção 1, p. 12447. Disponível em: $<$ http://www.planalto.gov.br/ccivil_03/leis/1950-1969/L5377.htm>. Acesso em: 6 dez. 2018.

Ministério da Educação. Comissão Especial de Estudos sobre Evasão nas Universidades Públicas Brasileiras. Diplomação, retenção e evasão nos cursos de graduação em instituições de ensino superior públicas. Brasília, DF: Andifes, 1996. Disponível em: <http://www.dominiopublico.gov.br/ download/texto/me001613.pdf>. Acesso em: 30 nov. 2017.

. Ministério da Educação. Resolução no 2, de 27 de setembro de 2013. Institui as Diretrizes Curriculares Nacionais para os cursos de graduação em Relações Públicas. Diário Oficial da União, Poder Executivo, Brasília, DF, 1 out. 2013. Seção 1, p. 28-29. Disponível em: <http://pesquisa.in.gov.br/ imprensa/jsp/visualiza/index.jsp?data $=01 / 10 / 2013 \&$ jornal $=1 \&$ pagina $=28 \&$ totalArquivos=96>. Acesso em: 2 out. 2014.

FERRARI, Maria Aparecida. A prática das relações públicas no cenário brasileiro e latino-americano. In: GRUNIG, James E.; FERRARI, Maria Aparecida; FRANÇA, Fábio. Relações públicas: teoria, contexto e relacionamentos. 2. ed. São Caetano do Sul: Difusão, 2011. p. 197-246.

FERRARI, Maria Aparecida; GROHS, Ana Cristina da Costa Piletti. Perfil e trajetória dos egressos de relações públicas da ECA/USP: subsídios para excelência acadêmica e competitividade no mercado de trabalho. In: Congresso Brasileiro Científico de Comunicação Organizacional e Relações Públicas, 9., 2015, Porto Alegre. Anais... Porto Alegre: EdiPUCRS, 2015. p. $127-148$.

INSTITUTO BRASILEIRO DE GEOGRAFIA E ESTATÍSTICA. São Borja. IBGE Cidades, Rio de Janeiro, 2017. Disponível em: <https://cidades.ibge. gov.br/brasil/rs/sao-borja/panorama>. Acesso em: 5 mar. 2018.

MADEIRA, Miguel Carlos; SILVA, Rosa Maria Alves. Ensinar na universidade: didática para professores iniciantes. Petrópolis: Vozes, 2015.

MARINI, Thereza. A função do ensino e a formação do professor universitário. São Paulo: Paulus, 2013. 
MOURA, Cláudia Peixoto. O curso de comunicação social no Brasil: do currículo mínimo às novas diretrizes curriculares. Porto Alegre: EdiPUCRS, 2002.

PACHECO, Eliezer; RISTOFF, Dilvo I. Educação superior: democratizando o acesso. Brasília, DF: Instituto Nacional de Estudos e Pesquisas Educacionais, 2004. (Série Documental, Textos para Discussão n. 12).

QUADROS, Daiane Franciele Morais. A evasão discente na universidade: o caso da UEPG. In: CONGRESSO NACIONAL DE EDUCAÇÃO, 11., 2013, Curitiba. Anais... Curitiba: Champagnat, 2013. p. 3065-3074. Disponível em: <http://educere.bruc.com.br/arquivo/pdf2013/8167_4450.pdf>. Acesso em: 8 out. 2018 .

RHODEN, Valmor. O ensino superior de relações públicas: formação digital, práticas e desafios na UFSM. 2013. 331 f. Tese (Doutorado em Comunicação Social) - Pontifícia Universidade Católica do Rio Grande do Sul, Porto Alegre, 2013.

RISTOFF, Dilvo I. Universidade em foco: reflexões sobre a educação superior. Florianópolis: Insular, 1999.

Construindo outra educação: tendências e desafios da educação brasileira. Florianópolis: Insular, 2011.

SILVA FILHO, Roberto Leal Lobo et al. Evasão no ensino superior brasileiro. Cadernos de Pesquisa, São Paulo, v. 37, n. 132, p. 641-659, set./dez. 2007.

UNIVERSIDADE FEDERAL DO PAMPA. Conselho Universitário. Resolução n 29, de 28 de abril de 2011. Aprova as normas básicas de graduação, controle e registro das atividades acadêmicas. Bagé: Conselho Universitário, 2011. Disponível em: <http://porteiras.r.unipampa.edu.br/portais/prograd/ files $/ 2011 / 06 /$ Resolu \%C3\%A7\%C3\%A3o-29-2011-Normas-B\%C3\%A1sicasde-Gradua\%C3\%A7\%C3\%A3o.pdf>. Acesso em: 4 dez. 2017.

- Coordenadoria de Apoio Pedagógico. A evasão na Unipampa: diagnosticando processos, acompanhando trajetórias e itinerários de formação. Responsáveis: Adriano Rodrigues José e Giovani Souza Andreoli. Bagé: CAP, 2011. Disponível em:<http://porteiras.r.unipampa.edu.br/ portais / cap/files/2010/07/Relat\%C3\%B3rio_final_evas\%C3\%A3o-naUNIPAMPA_out20111.pdf>. Acesso em: 30 nov. 2017.

. Curso de Relações Públicas. Pesquisa de evasão do Curso de Relações

Públicas - Ênfase em Produção Cultural. Relatório impresso, disponível na Coordenação do Curso. São Borja: Unipampa, 2013.

- Projeto político-pedagógico do Curso de Relações Públicas da Unipampa. São Borja: Unipampa, 2015. Disponível em: <http://cursos. unipampa.edu.br/cursos/relacoespublicas/pdi-ppc/>. Acesso em: 22 nov. 2017. 
